\title{
A bispecific diabody directed against prostate-specific membrane antigen and CD3 induces T-cell mediated lysis of prostate cancer cells
}

\author{
P. Bühler $\cdot$ P. Wolf $\cdot$ D. Gierschner $\cdot$ I. Schaber $\cdot$ A. Katzenwadel $\cdot$ \\ W. Schultze-Seemann $\cdot$ U. Wetterauer $\cdot$ M. Tacke $\cdot$ M. Swamy $\cdot$ \\ W. W. A. Schamel · U. Elsässer-Beile
}

Received: 15 December 2006 / Accepted: 23 May 2007 / Published online: 20 June 2007

(C) Springer-Verlag 2007

\begin{abstract}
Background Although cancer of the prostate is one of the most commonly diagnosed cancers in men, no curative treatment currently exists after its progression beyond resectable boundaries. Therefore, new agents for targeted treatment strategies are needed. Cross-linking of tumor antigens with $\mathrm{T}$-cell associated antigens by bispecific monoclonal antibodies have been shown to increase antigen-specific cytotoxicity in T-cells. Since the prostate-specific membrane antigen (PSMA) represents an excellent tumor target, immunotherapy with bispecific diabodies could be a promising novel treatment option for prostate cancer.

Methods A heterodimeric diabody specific for human PSMA and the T-cell antigen CD3 was constructed from

P. Bühler and P. Wolf equally contributed to the work.

P. Bühler · P. Wolf · D. Gierschner · I. Schaber · A. Katzenwadel

W. Schultze-Seemann · U. Wetterauer · U. Elsässer-Beile ( $\triangle)$

Department of Urology, Experimental Urology,

University of Freiburg, Breisacher Str. 117,

79106 Freiburg, Germany

e-mail: ursula.elsaesser@uniklinik-freiburg.de

P. Bühler

Faculty of Biology, University of Freiburg,

Schänzle Str. 1, 79104 Freiburg, Germany

M. Tacke

Institute of Molecular Medicine and Cell Research,

University of Freiburg, Stefan-Meier-Strasse 17,

79106 Freiburg, Germany

M. Swamy · W. W. A. Schamel

Department of Molecular Immunology,

Max-Planck-Institute for Immunobiology and

University of Freiburg, Biologie III,

Stübeweg 51, 79108 Freiburg, Germany
\end{abstract}

the DNA of anti-CD3 and anti-PSMA single chain Fv fragments (scFv). It was expressed in E. coli using a vector containing a bicistronic operon for co-secretion of the hybrid $\mathrm{scFv} \mathrm{V}_{\mathrm{H}} \mathrm{CD} 3-\mathrm{V}_{\mathrm{L}}$ PSMA and $\mathrm{V}_{\mathrm{H}} \mathrm{PSMA}-\mathrm{V}_{\mathrm{L}} \mathrm{CD}$ 3. The resulting PSMAxCD3 diabody was purified from the periplasmic extract by immobilized metal affinity chromatography (IMAC). The binding properties were tested on PSMA-expressing prostate cancer cells and PSMA-negative cell lines as well as on Jurkat cells by flow cytometry. For in vitro functional analysis, a cell viability test (WST) was used. For in vivo evaluation the diabody was applied together with human peripheral blood lymphocytes (PBL) in a C4-2 xenograft-SCID mouse model.

Results By Blue Native gel electrophoresis, it could be shown that the PSMAxCD3 diabody is mainly a tetramer. Specific binding both to CD3-expressing Jurkat cells and PSMA-expressing C4-2 cells was shown by flow cytometry. In vitro, the diabody proved to be a potent agent for retargeting PBL to lyze C4-2 prostate cancer cells. Treatment of SCID mice inoculated with C4-2 tumor xenografts with the diabody and PBL efficiently inhibited tumor growth.

Conclusions The PSMAxCD3 diabody bears the potential for facilitating immunotherapy of prostate cancer and for the elimination of minimal residual disease.

Keywords PSMAxCD3 bispecific diabody .

Prostate cancer $\cdot$ T-cell targeting $\cdot$ Immunotherapy

\section{Introduction}

Currently, there is no effective therapy for advanced prostate cancer, which necessitates the development of new and targeted therapies [13]. Among the different identified prostate antigens, the prostate-specific membrane antigen 
(PSMA) has been shown to represent an excellent target for immunotherapy because it is (1) selectively expressed in the prostate, (2) abundantly expressed as protein at all stages and even upregulated in androgen-insensitive metastatic disease, (3) presented at the cell surface without being released into the circulation, and (4) associated with enzymatic or signaling activity [10].

In the field of cancer immunotherapy research, the retargeting of T-cells to tumor cells by bispecific antibodies (BsAbs) is an appealing therapeutic concept because cytotoxic T-cells range among the most potent effector cells of the immune system $[31,32]$. The promise of BsAbs is an antibody target-dependent, polyclonal T-cell response. This does not depend on a specific T-cell receptor and $\mathrm{MHC}$ class I/peptide complex, and can support serial killing by cytotoxic T cells. Various strategies have been utilized for the creation of BsAbs. In a first generation, they have been produced mainly by using quadroma technology [1]. The most effective approach for tumor rejection appeared to be targeting via the CD3 component of the T-cell receptor complex molecule. The feasibility and effectiveness of this immunotherapeutic concept have been studied extensively in pre-clinical models and in some cases also in clinical trials [2, 3]. However, the immunogenicity of these BsAbs derived from rodent monoclonal antibodies was a major drawback for their clinical use. Additionally, their production and purification in large quantities proved to be difficult.

Recent advances in genetic engineering enabled the preparation of recombinant BsAbs as dimeric antibody fragments [12]. Diabodies are the smallest available BsAbs, and the distance between the two antigen-binding sites is sufficient to link two cells [21]. This compact size contributes to a low immunogenicity and a high tumor penetration [34].

Kipriyanov et al. constructed a bispecific diabody with dual specificity for both the human B-cell antigen CD19 and the $\varepsilon$-chain of the CD3/T-cell receptor complex, which is able to retarget human lymphocytes to malignant B-cells [16]. This construct was used in the present study as a model for the generation of a diabody against PSMA and the CD3 complex.

\section{Material and methods}

\section{Cell lines}

The human prostate carcinoma LNCaP subline C4-2 was used as PSMA-positive target. As PSMA-negative control the prostate cancer cell lines DU 145 and PC-3 were used. The Jurkat cell line served as positive target for CD3 and CD28.
Cells were purchased from the American Type Culture Collection (ATCC, Rockville, MD, USA) and cultured in RPMI 1640 medium supplemented with penicillin (100 U/ $\mathrm{ml})$, streptomycin $(100 \mathrm{mg} / \mathrm{l})$ and $10 \%$ fetal calf serum (Biochrom, Berlin, Germany) at $37^{\circ} \mathrm{C}$ in a humidified atmosphere of $5 \% \mathrm{CO}_{2}$.

Monoclonal antibodies and scFv

The anti-PSMA scFv, called A5, directed against native cell-adherent PSMA was obtained in our group from the monoclonal antibody (mAb) 3/A12 as described previously. This scFv could be shown to be highly specific for PSMA-expressing prostate cancer cells [8, 33]. The anti-CD3 scFv was obtained from Dr. Kipriyanov, DKFZ, Heidelberg, Germany [14]. Anti-CD28 mAb (15E8) was obtained from Dr. Miedema, Netherlands Red Cross Blood Transfusion Service.

Expression vectors for diabody construction

The E. coli K12 strain XL1-blue (Stratagene, La Jolla, CA, USA) was used as the cloning and expression host. The plasmid pHOG-3-19, containing the recombinant DNA for $\mathrm{V}_{\mathrm{H}} \mathrm{CD} 3$ and $\mathrm{V}_{\mathrm{L}} \mathrm{CD} 19$, and the plasmid pHOG-19-3, containing the recombinant DNA for $\mathrm{V}_{\mathrm{H}} \mathrm{CD} 19$ and $\mathrm{V}_{\mathrm{L}} \mathrm{CD}$, were obtained from Dr. Kipriyanov, DKFZ, Heidelberg, Germany [16].

ScFv and diabody expression and purification

E. coli XL1-blue cells (La Jolla, CA, USA) transformed with the plasmid for diabody or scFv were grown overnight in 2xYT-AG-medium, then diluted 1:20 and grown as $600 \mathrm{ml}$ cultures at $37^{\circ} \mathrm{C}$. When cultures reached OD 0.8 , bacteria were pelleted by centrifugation at $1,500 \mathrm{~g}$ for $10 \mathrm{~min}$ and resuspended in the same volume of fresh $2 \mathrm{xYT}$ medium containing $50 \mu \mathrm{g} / \mathrm{ml}$ ampicillin, $0.4 \mathrm{M}$ sucrose and $1 \mathrm{mM}$ IPTG. Then the bacteria were incubated at room temperature for 18-20 h. Cells were harvested by centrifugation at $5,000 \mathrm{~g}$ for $10 \mathrm{~min}$ and $4{ }^{\circ} \mathrm{C}$. To isolate soluble periplasmic proteins, the pelleted bacteria were resuspended in $30 \mathrm{ml}$ of ice-cold $50 \mathrm{mM}$ Tris- $\mathrm{HCl}, 20 \%$ sucrose, $1 \mathrm{mM}$ EDTA ( $\mathrm{pH} 8.0$ ). After incubation for $1 \mathrm{~h}$ on ice, the spheroblasts were centrifuged at $20,000 \mathrm{~g}$ for $30 \mathrm{~min}$ at $4{ }^{\circ} \mathrm{C}$ yielding soluble periplasmic extract in the supernatant, which was dialyzed against $50 \mathrm{mM}$ Tris- $\mathrm{HCl}, 1 \mathrm{M}$ $\mathrm{NaCl}$, (pH 7.0).

Purification was achieved by immobilized metal affinity chromatography (IMAC). This was performed using a $1 \mathrm{ml}$ column of chelating Sepharose (Amersham Biosciences, Freiburg, Germany) charged with $\mathrm{Ni}^{2+}$ and equilibrated with a buffer containing $50 \mathrm{mM}$ Tris- $\mathrm{HCl}$ and $1 \mathrm{M} \mathrm{NaCl}$ 
( $\mathrm{pH}$ 7.0). The periplasmatic extract was loaded on the column, washed with 20 column volumes of equilibration buffer containing $30 \mathrm{mM}$ imidazole and then eluted with the same buffer containing $250 \mathrm{mM}$ imidazole. The eluted material was dialyzed against PBS. Determination of the protein content was performed with the Micro BCA Protein Reagent Kit (Pierce Biotechnology, Rockford, IL, USA) according to the manufacturer's instructions.

\section{Western blot analysis}

SDS-PAGE was performed by standard procedures according to the manufacturer's instructions (Invitrogen, Karlsruhe, Germany). For Western blotting, the diabody and scFvs were subjected to SDS-PAGE and transferred to nitrocellulose membranes. The blots were blocked overnight in PBS containing 5\% non-fat milk and incubated with a peroxidase-coupled anti-human-c-myc antibody (Roche Diagnostics, Mannheim, Germany) for $1 \mathrm{~h}$, and then developed by using 3,3'-diaminobenzidine as substrate. For Blue Native (BN)-PAGE [22, 23] analysis, the diabody and scFvs were diluted to $0.2 \mu \mathrm{g}$ in $10 \mu \mathrm{l} \mathrm{BN}$ buffer (500 mM 6-aminohexanoic acid, $20 \mathrm{mM} \mathrm{NaCl,} \mathrm{10 \%} \mathrm{glyc-}$ erol, $2 \mathrm{mM}$ EDTA, $20 \mathrm{mM}$ bis-Tris, $\mathrm{pH} 7$ and protease inhibitors) and resolved on 4-18\% BN-PAGE as described [29]. The proteins were transferred semi-dry to a PVDF membrane, and Western blotting was performed as above, and developed with the ECL chemiluminescence system. The high molecular weight calibration kit for native electrophoresis (GE Healthcare) was also loaded and stained with Coomassie brilliant blue for molecular weight standards.

\section{Flow cytometry}

The target cells were freshly harvested from tissue culture flasks and a single cell suspension was prepared in PBS with $3 \% \mathrm{FCS}$ and $0.1 \% \mathrm{NaN}_{3}$. Approximately, $10^{5}$ cells were incubated with $50 \mu \mathrm{l}$ of scFv or diabody for $1 \mathrm{~h}$ on ice. After three rounds of washing with PBS, $25 \mu \mathrm{l}$ anti-human-c-myc $\mathrm{mAb}$ (Roche Diagnostics, Mannheim, Germany) was added at $10 \mu \mathrm{g} / \mathrm{ml}$ and incubated for $40 \mathrm{~min}$ on ice. After three washings with PBS, the cells were incubated with $25 \mu \mathrm{l}$ of goat anti-mouse Ig-RPE (Becton Dickinson, Mountain View, CA, USA) for $40 \mathrm{~min}$ on ice. For inhibition experiments with mouse anti-PSMA mAb, a rat anti-c-myc mAb (Serotec LTD, Oxford, UK) and goat anti-rat IgG $(\mathrm{H}+\mathrm{L})$ RPE (Catlag Lab Burlingame, CA, USA) were taken. The cells were then washed repeatedly and resuspended in $200 \mu \mathrm{l} \mathrm{PBS}$ containing $1 \mu \mathrm{g} / \mathrm{ml}$ propidium iodide, $3 \% \mathrm{FCS}$ and $0.1 \% \mathrm{NaN}_{3}$. The relative fluorescence of stained cells was measured using a FACScan ${ }^{\circledR}$ flow cytometer and the CellQuest ${ }^{\circledR}$ software (Becton Dickinson). Mean fluores- cence intensity values (MFI) were considered after subtraction of the background staining with secondary antibody and RPE-labeled goat anti-mouse Ig alone.

\section{Preparation of effector cells}

Human peripheral blood mononuclear cells (PBMC) were isolated from fresh buffy coats of random donors by Ficoll (Pharmacia, Freiburg, Germany) density gradient centrifugation. The cells of the interphase were washed twice, counted and tested for viability with trypan blue dye. The PBMC were incubated overnight in $10 \mathrm{ml}$ RPMI 1640 medium supplemented with penicillin (100 U/l), streptomycin $(100 \mathrm{mg} / \mathrm{l})$ fetal calf serum $(10 \%)$ and low-dose IL-2 $(10 \mathrm{U} / \mathrm{ml})$ at $37^{\circ} \mathrm{C}$, $5 \% \mathrm{CO}_{2}$ leading to the adherence of monocytes. The nonadherent PBL were used as effector cells.

\section{Measurement of in vitro cytotoxicity}

The metabolism of the red tetrazolium salt WST to a watersoluble formazan dye was determined according to the manufacturer's instructions (Roche Diagnostics, Mannheim, Germany). Target cells were seeded at $1.5 \times 10^{4}$ cells/well of a 96-well plate and grown for $24 \mathrm{~h}$ until a confluent cell layer was formed. Dilutions of the diabody in aliquots of $50 \mu \mathrm{l} /$ well were added to the plates together with the effector cells at a target:effector ratio of 1:10 and incubated for $48 \mathrm{~h}$ at $37^{\circ} \mathrm{C}$ and $5 \% \mathrm{CO}_{2}$. After this time, the cultures were pulsed with $15 \mu \mathrm{l} /$ well WST reagent and incubated for $90 \mathrm{~min}$ at $37^{\circ} \mathrm{C}$ and $5 \% \mathrm{CO}_{2}$. Then the spectrophotometrical absorbance of the samples was measured at $450 \mathrm{~nm}$ (reference $690 \mathrm{~nm}$ ). As control for the PBL background in each WST experiment, PBL were incubated at the same lymphocyte concentration without tumor cells for $48 \mathrm{~h}$ and developed with WST. The value of these wells was then subtracted from the values of the test wells.

\section{SCID mouse Xenograft model}

Six-week-old SCID mice were purchased from Charles River Laboratories (Sulzfeld, Germany). The animals were kept under sterile and standardized environmental conditions $\left(20 \pm 1^{\circ} \mathrm{C}\right.$ room temperature, $50 \pm 10 \%$ relative humidity, $12 \mathrm{~h}$ light-dark rhythm) and received autoclaved food, water and bedding. All experiments were performed according to the German animal protection law with permission from the responsible local authorities. For tumor inoculation, $2 \times 10^{6} \mathrm{C} 4-2$ cells in $100 \mu \mathrm{l}$ PBS were mixed with $100 \mu \mathrm{l}$ Matrigel (Collaborative Biomedical Products, Chicago, USA) at $4^{\circ} \mathrm{C}$ and administered s.c. at the right flank of each animal. Growing tumors were measured daily using a caliper in two perpendicular dimensions. Between day 6 and 12 after tumor inoculation, the animals were 
treated i.v. either with peripheral blood lymphocytes (PBL) plus diabody, or with PBL alone, or with the vehicle. When the tumors of the control group reached a diameter of $12 \mathrm{~mm}$, the animals were killed by $\mathrm{CO}_{2}$ gas overdose. From the tumor diameters, the mean radius $(r)$ and hence the tumor volumes were calculated using the formula $V=4$ / $3 \pi r^{3}$. Statistical analysis of the mean tumor volume of the corresponding treatment groups versus the vehicle control group was calculated performing a Student's $t$ test.

\section{Results}

Construction of the diabody plasmid

In the plasmid pHOG-3-19, the sequence for $\mathrm{V}_{\mathrm{L}} \mathrm{CD} 19$ was exchanged against $\mathrm{V}_{\mathrm{L}}$ PSMA by a PCR and the restriction sites Hind III and Not I, thus generating the plasmid pHOGCD-3-PSMA (Fig. 1a). In the plasmid pHOG-19-3, the sequence of $\mathrm{V}_{\mathrm{H}} \mathrm{CD} 19$ was exchanged against $\mathrm{V}_{\mathrm{H}}$ PSMA by using the restriction sites NcoI and Hind III for the generation of pHOG-PSMACD-3 (Fig. 1b). The expression plasmid of the PSMAxCD3 diabody for co-secretion of the two hybrid scFvs was constructed by ligation of the $\mathrm{Bgl} \mathrm{II/XbaI}$ restriction fragment from pHOGCD-3-PSMA comprising the vector backbone and the $\mathrm{Bgl} \mathrm{II} / \mathrm{Xba} \mathrm{I}$ fragment from pHOG-PSMACD-3 (Fig. 1c). Both hybrid scFv operons are followed by sequences coding for a human c-myc tag for immunodetection and a hexahistidine tag for purification.

Diabody expression and purification

Upon induction with IPTG, the PSMAxCD3 diabody was expressed by co-secretion of the two hybrid scFvs
$\mathrm{V}_{\mathrm{H}}$ PSMA- $\mathrm{V}_{\mathrm{L}} \mathrm{CD} 3$ and $\mathrm{V}_{\mathrm{H}} \mathrm{CD} 3-\mathrm{V}_{\mathrm{L}}$ PSMA from E.coli XL1blue cells as periplasmatic native protein and was also released into the culture medium. The periplasmatic extract was purified by IMAC. Yields were estimated by the protein content according to BCA-testing and the $32 \mathrm{KD}$ band on SDS-gels compared to a BSA standard. Between 100 and $300 \mu \mathrm{g}$ diabody per liter of culture were obtained from the periplasmatic extract. Purity of the diabody was determined by SDS-PAGE and Coomassie brilliant blue staining (Fig. 2a). The diabody was kept under sterile conditions and stored at $-80^{\circ} \mathrm{C}$.

\section{Analysis of the PSMAxCD3 diabody}

To analyze the quaternary structure of the diabody, it was resolved by gel-electrophoresis in either reducing denaturing conditions (SDS-PAGE) or native conditions (BNPAGE), followed by Western blotting. Under denaturing, reducing conditions the PSMAxCD3 diabody was detected as protein double band at $32 \mathrm{kD}$ (Fig. $2 \mathrm{~b}$, lane 1), corresponding to the two hybrid scFvs, $\mathrm{V}_{\mathrm{H}} \mathrm{PSMA}-\mathrm{V}_{\mathrm{L}} \mathrm{CD} 3$ and $\mathrm{V}_{\mathrm{H}} \mathrm{CD} 3-\mathrm{V}_{\mathrm{L}}$ PSMA. Separation of the diabody into a double band was only seen by Western blotting and not in the Coomassie-stained SDS gel, as smaller amounts were loaded for Western blotting, which allows higher resolution. When separated under native conditions by BN-PAGE [28, 29], the diabody is mainly present as a band whose molecular weight ( $\sim 150 \mathrm{kD})$ corresponds to a tetramer (Fig. 2c, lane 1). Additional bands of higher MW are visible, possibly representing complexes of a larger order. The anti-PSMA scFv alone is also a tetramer (lane 2), whereas the anti-CD3 $\mathrm{scFv}$ is a dimer at $\sim 70 \mathrm{kD}$ (Fig. 2c, lane 3). Together these findings indicate that the variable regions of the anti-PSMA $\mathrm{scFv}$ are responsible for tetramerization. a

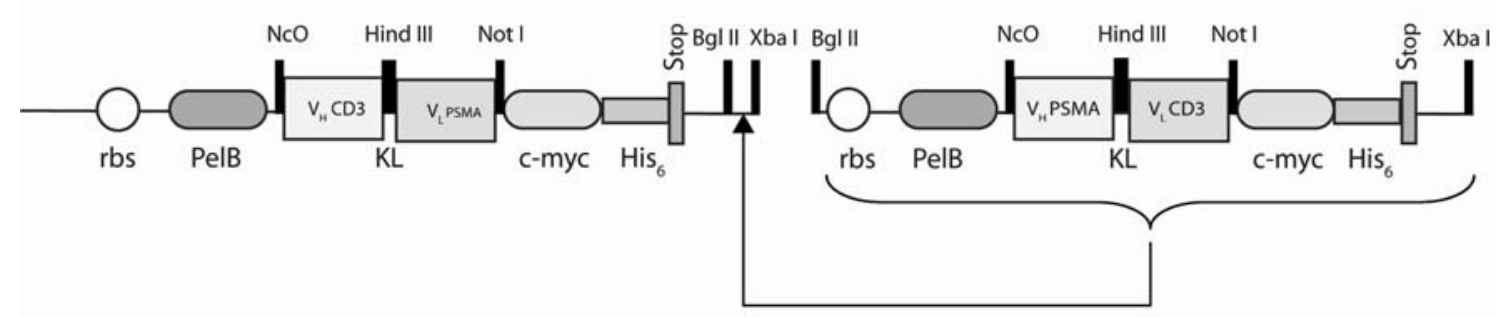

c

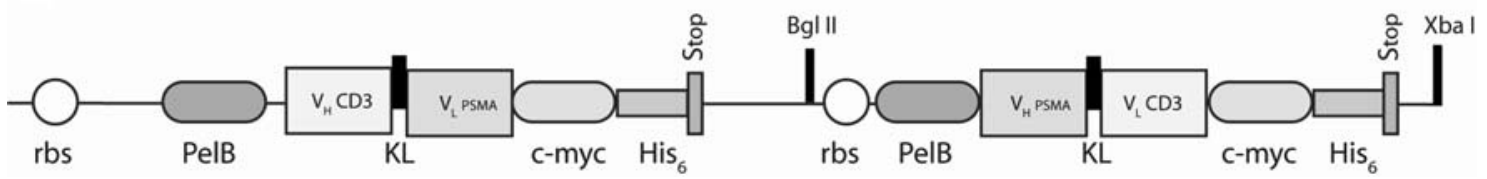

Fig. 1 Construction scheme for the PSMAxCD3 diabody plasmid (c) from the hetero $\mathrm{scFv} \mathrm{V}_{\mathrm{H}} \mathrm{CD} 3-\mathrm{V}_{\mathrm{L}}$ PSMA (a) and $\mathrm{V}_{\mathrm{H}} \mathrm{PSMA}-\mathrm{V}_{\mathrm{L}} \mathrm{CD} 3$ (b). The positions of the sequences of the variable regions of the light and heavy chains of the anti-PSMA-scFv and the anti-CD3-scFv, the ribosome binding sites $(r b s)$, pelB leader sequences (pelB), c-myc epitopes $(c-m y c)$, hexa-histidine tags $\left(\mathrm{His}_{6}\right)$ and stop codons ( $\left.\mathrm{stop}\right)$ are indicated 

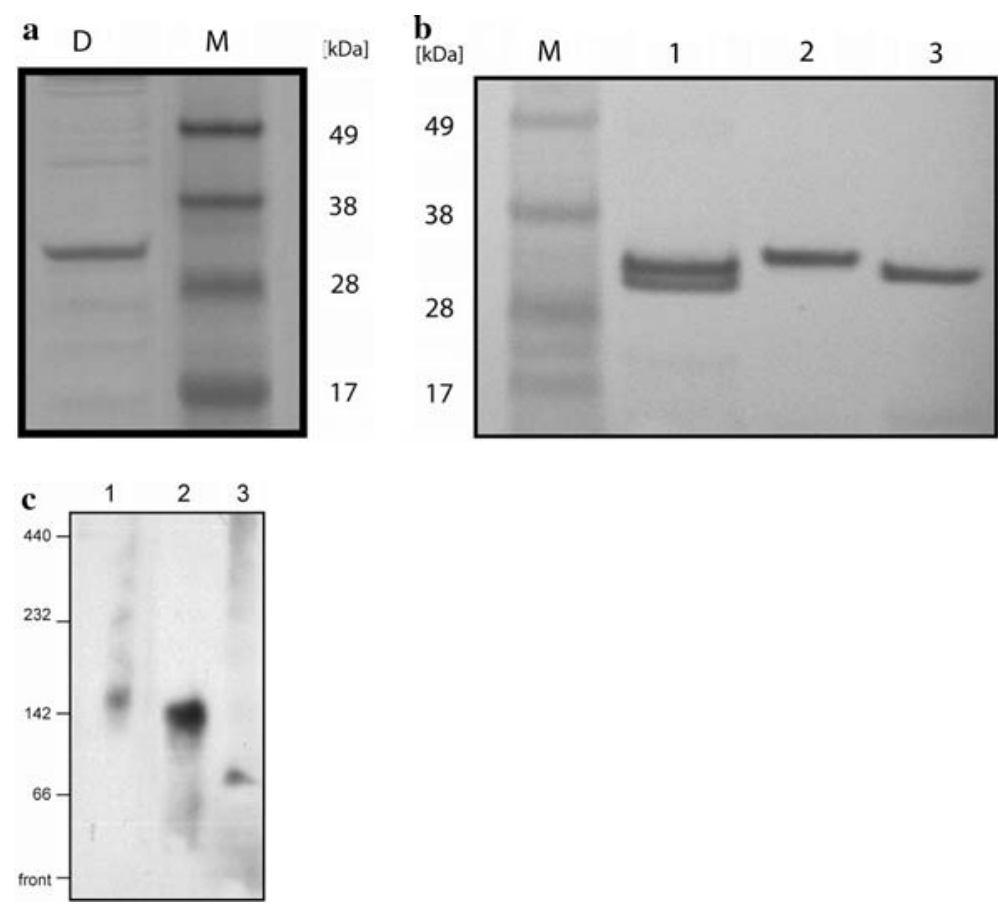

Fig. 2 a SDS-PAGE of the PSMAxCD3 diabody (lane D). The gel was stained with Coomassie brilliant blue. Lane $M$ contains a molecular weight marker. b Gel electrophoresis under denaturing, reducing conditions of PSMAxCD3 diabody (lane 1), anti-PSMA scFv (lane 2) and anti-CD3 $\mathrm{scFv}$ (lane 3). Proteins were subjected to reducing SDSPAGE and transferred to a Western blot membrane. The blot was developed with peroxidase-coupled anti-c-myc-mAb, and 3,3'-diamino-

benzidine. Lane $M$ contains a prestained molecular weight marker. $\mathbf{c}$ Gel electrophoresis under native conditions of PSMAxCD3 diabody (lane 1), anti-PSMA scFv (lane 2) and anti-CD3 scFv (lane 3). Proteins were separated by BN-PAGE and Western blotted with the peroxidasecoupled anti-c-myc-mAb and the ECL detection system. The molecular weights of the native protein standards are indicated on the left in kilo Daltons

Antigen-binding specificity of the PSMAxCD3 diabody and the parental scFvs

Flow cytometric experiments demonstrated a specific binding of the PSMAxCD3 diabody to PSMA-positive C4-2 cells (Fig. 3b) and to CD3-expressing Jurkat cells (Fig. 3f). The mean fluorescence intensities (MFI) at saturating conditions were about 30 on C4-2 cells and about 15 on Jurkat cells and therefore comparable to those obtained using the parental monospecific anti-PSMA scFv (Fig. 3a) and anti-CD3 scFv (Fig. 3e). In contrast to the PSMAxCD3 diabody, the separately induced hybrid $\mathrm{scFv} \mathrm{V}_{\mathrm{H}} \mathrm{PSMA}$ $\mathrm{V}_{\mathrm{L}} \mathrm{CD} 3$ and $\mathrm{scFv} \mathrm{V}_{\mathrm{H}} \mathrm{CD} 3-\mathrm{V}_{\mathrm{L}}$ PSMA did not show any binding to either $\mathrm{C} 4-2$ cells (Fig. 3c, d) or Jurkat cells (Fig. $3 \mathrm{~g}, \mathrm{~h})$. This indicates that both variable regions $\left(V_{H}\right.$ and $V_{L}$ ) are necessary to reconstitute the binding site of an antibody. The saturation curves of the PSMAxCD3 diabody and the parental anti-PSMA scFv at concentrations between 0.5 and $500 \mathrm{nM}$ on C4-2 cells is shown in Fig. 4a. From this graph, a half-maximal saturation was calculated to be $100 \mathrm{nM}$ for the diabody and $80 \mathrm{nM}$ for the scFv. The corresponding curves of the diabody and the anti-CD3 $\mathrm{scFv}$ on Jurkat cells are shown in Fig. 4b. Half-maximal saturation was calculated to be $30 \mathrm{nM}$ for the diabody and the scFv.

Binding of the PSMAxCD3 diabody to C4-2 cells was inhibited by parental monoclonal antibody 3/A12 (Fig. 5a) and binding to Jurkat cells was inhibited by mAb OKT3 (Fig. 5b).

No binding of the diabody was found on PSMA- and CD3-negative DU145 and PC-3 cells. This is in accordance with the parental anti-PSMA scFv, which was shown to be highly specific for PSMA-expressing cells and did not bind to the PSMA-negative target cell lines DU 145, PC-3, HeLa, MCF7, HCT15, MB453, K562 and SW20 [33]. The specificity of the parental anti-CD3 $\mathrm{scFv}$ has also been shown previously [14].

The in vitro stability of the diabody was tested by binding experiments before and after incubation at $37^{\circ} \mathrm{C}$ for $24 \mathrm{~h}$. Under these conditions, the binding capacity was reduced by $25 \%$. Storage of the diabody at $4^{\circ} \mathrm{C}$ or frozen at $-20^{\circ} \mathrm{C}$ for several weeks brought about no alteration in the binding capacity.

Induction of specific cytotoxicity by the PSMAxCD3 diabody in vitro

The ability of the bispecific diabody to induce tumor cell lysis by redirecting T-cell mediated cytotoxicity was inves- 
Fig. 3 Binding of anti-PSMA scFv (a), PSMAxCD3 diabody (b), hybrid scFv $\mathrm{V}_{\mathrm{H}}$ PSMA$\mathrm{V}_{\mathrm{L}} \mathrm{CD} 3$ (c) and hybrid $\mathrm{scFv}$ $\mathrm{V}_{\mathrm{H}} \mathrm{CD} 3-\mathrm{V}_{\mathrm{L}}$ PSMA (d) to PSMA-positive C4-2 cells. Binding of anti-CD3 scFv (e), PSMAxCD3 diabody (f), hybrid scFv $\mathrm{V}_{\mathrm{H}} \mathrm{PSMA}-\mathrm{V}_{\mathrm{L}} \mathrm{CD} 3$ (g) and hybrid $\mathrm{scFV} \mathrm{V}_{\mathrm{H}} \mathrm{CD} 3-\mathrm{V}_{\mathrm{L}}$ PSMA (h) to CD3-positive Jurkat cells. Cells were stained with diabody or scFv at $300 \mathrm{nM}$, mouse-anti$\mathrm{c}-\mathrm{myc} \mathrm{mAb}$ and goat anti-mouse Ig-RPE. Histograms represent logarithms of PE-fluorescence on flow cytometer. Negative control (gray histograms) with mouse-anti-c-myc mAb, and goat anti-mouse Ig-RPE

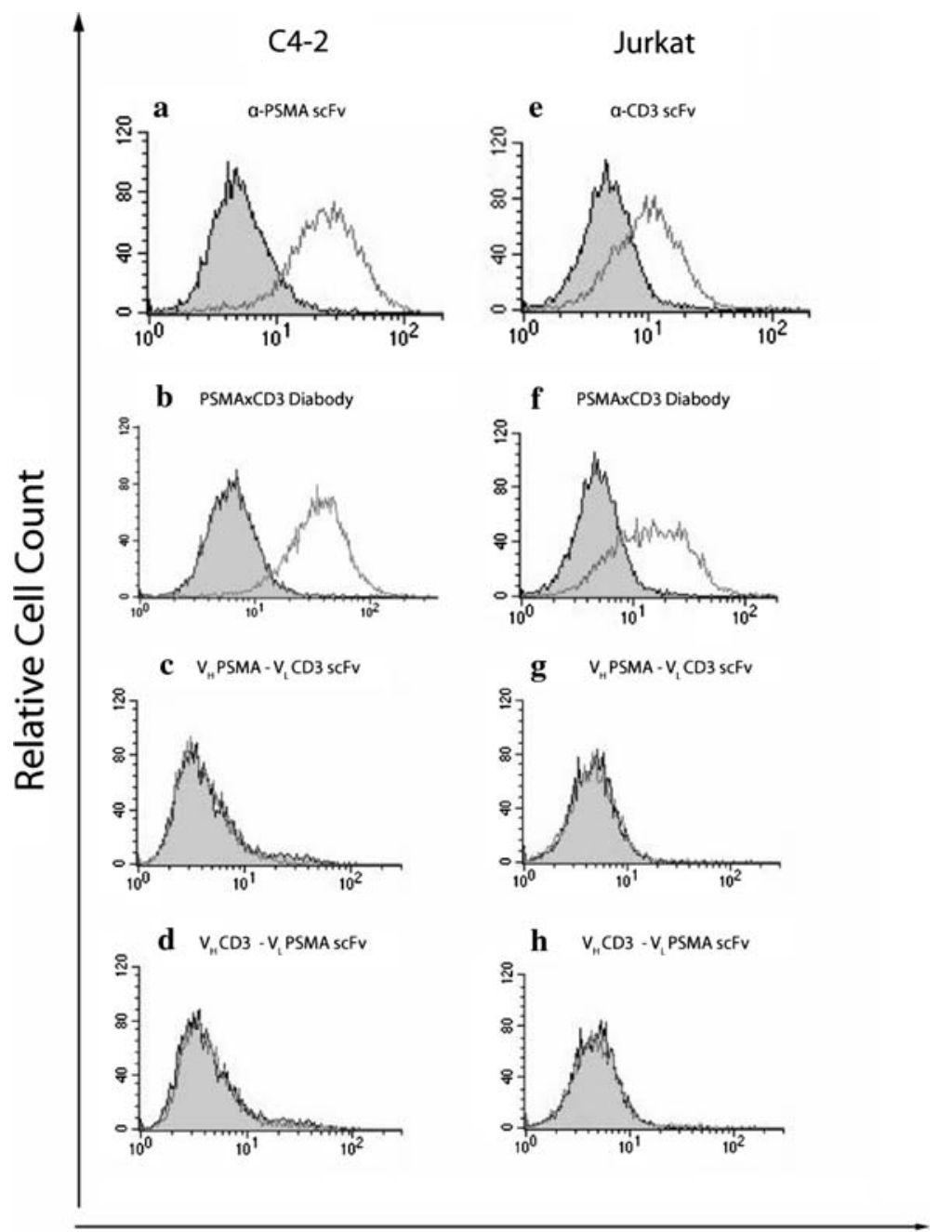

Mean Fluorescence Intensity tigated with PBL from healthy donors, which were monocyte depleted. PSMA-expressing C4-2 prostate cancer cells served as target cells and PSMA-negative DU-145 cells as controls.

In these experiments with an effector-target ratio of 10:1, the PSMAxCD3 diabody appeared to be potent in retargeting PBL to lyze the PSMA-positive C4-2 cells, whereas PSMA-negative DU145 cells were not lyzed at the same conditions (Fig. 6a). PBL from different donors varied as seen by the error bars. The PBL alone (at ET ratio 10:1) and the diabody alone at $15 \mathrm{nM}$ were not toxic to both cell lines. Cytotoxicity could be blocked by addition of an excess of parental mAb 3/A12 (Fig. 6b). The addition of anti-PSMA scFv or anti-CD3 scFv together with PBL showed only minimal cytotoxic activity compared to the PSMAxCD3 diabody (Fig. 7). Addition of anti-CD28 mAb for co-stimulation at concentrations between $100 \mu \mathrm{g}$ and $5 \mathrm{mg} / \mathrm{ml}$ brought about no enhancement of the diabody effects on C4-2 cells (data not shown).
Effect of the PSMAxCD3 diabody on xenotransplanted C4-2 tumors in SCID mice

The in vivo effects of the PSMAxCD3 diabody were tested in SCID mice xenotransplanted with the human LNCaP subline C4-2. Mice were engrafted with $2 \times 10^{6} \mathrm{C} 4-2$ cells s.c., which was shown to generate palpable tumors in more than $95 \%$ of the animals.

In a first series of four animals, toxicity of the PSMAxCD3 diabody was tested at doses of 5, 10, 15 and $20 \mu \mathrm{g}$ per injection. Doses up to $15 \mu \mathrm{g}$ were well tolerated.

For therapy, a series of 21 animals were used. On day 6 after tumor inoculation, the animals were randomized into three groups of seven animals. Group a was treated with $5 \times 10^{6} \mathrm{PBL}$ as effector cells on day 6 and additionally with $10 \mu \mathrm{g}$ PSMAxCD3 diabody on days $6,7,10,11$, and 12 . Group b was treated with $5 \times 10^{6}$ human PBL on day 6 . The animals of group $\mathrm{c}$ were treated with saline vehicle. All animals were killed on day 20 after tumor inoculation, 
Fig. 4 Saturation curves of the PSMAxCD3 diabody and the parental anti-PSMA scFv to PSMA-positive C4-2 cells (a) and of PSMAxCD3 diabody and parental anti-CD3 scFv to CD3-positive Jurkat cells (b) at concentrations between 0.5 and $500 \mathrm{nM}$
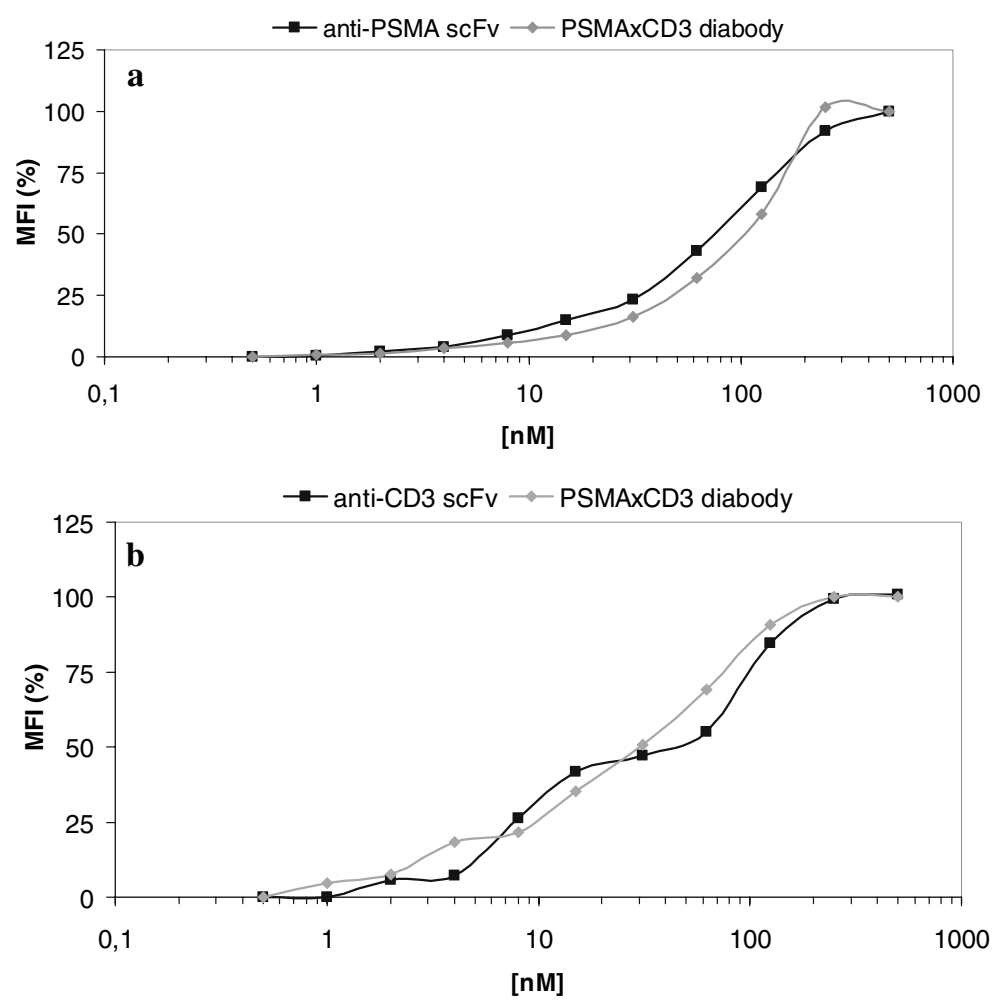
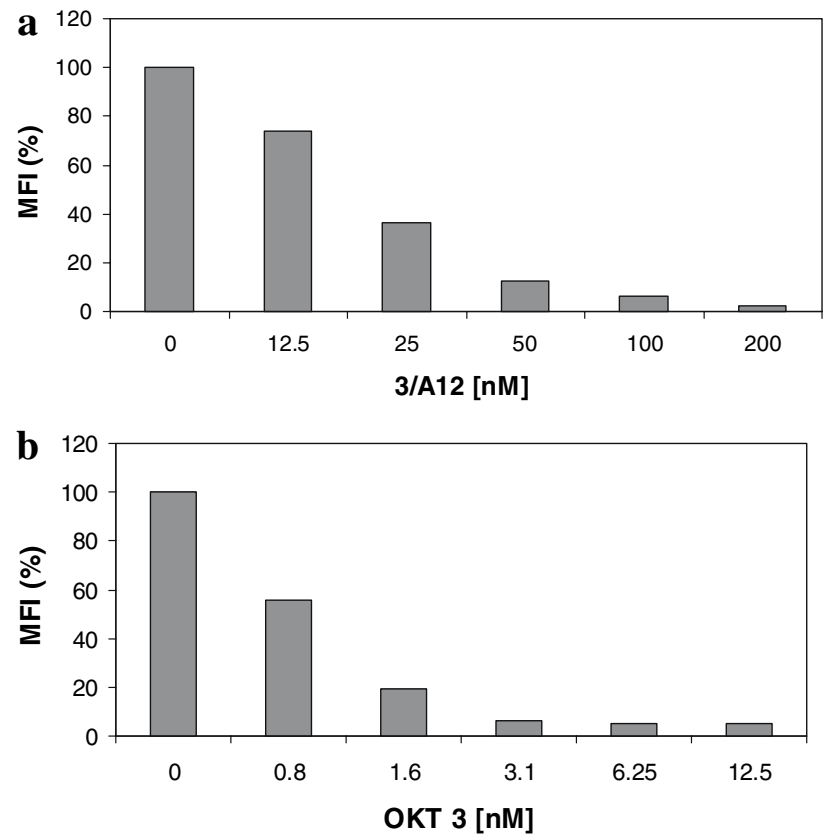

Fig. 5 Inhibition of the binding of PSMAxCD3 diabody to C4-2 cells by parental mAb 3/A12 (a) and to Jurkat cells by parental mAb OKT3 (b). Cells were preincubated with the mAb at different concentrations $(5-200 \mathrm{nM})$ and then stained with PSMAxCD3 diabody at $200 \mathrm{nM}$, rat anti-c-myc $\mathrm{mAb}$ and goat anti-rat $\mathrm{IgG}(\mathrm{H}+\mathrm{L})-\mathrm{RPE}$

when the tumors of the control animals had reached $12 \mathrm{~mm}$ diameter and/or begun to ulcerate.

In the saline-treated control group, the animals developed fast growing tumors between day 10 and 15 after tumor inoculation. In contrast, animals receiving human PBL showed reduced tumor growth. Animals receiving human PBL and additionally PSMAxCD3 diabody showed a delayed starting point of tumor growth and, finally, clearly reduced tumor growth (Fig. 8). The differences in the mean tumor volume of the animals of group a (diabody + PBL) and group c (vehicle) proved to be significant $(P=0.001)$, as well as the differences in the mean tumor volume of the animals of group a and group $\mathrm{b}$ (PBL alone) were significant $(P=0.04)$.

\section{Discussion}

The limited options in the treatment of prostate cancer have encouraged the search for new immunotherapeutic strategies. The retargeting of cellular effector systems by bispecific antibodies is a promising approach. Such recombinant diabodies have been generated against a number of tumorassociated antigens, but not yet against prostate cancer. By virtue of its abundant and restricted surface expression on prostate epithelial cells, PSMA represents an attractive antigen for a targeted therapy. However, in contrast to other tumor-associated antigens [19], there are only very few approaches that use PSMA. The reason for this may be that only few mAbs and scFvs binding to cell-adherent PSMA have yet been published [5, 11, 17, 20, 30].

For the construction of the PSMAxCD3 diabody described in the present paper, we used the recombinant 

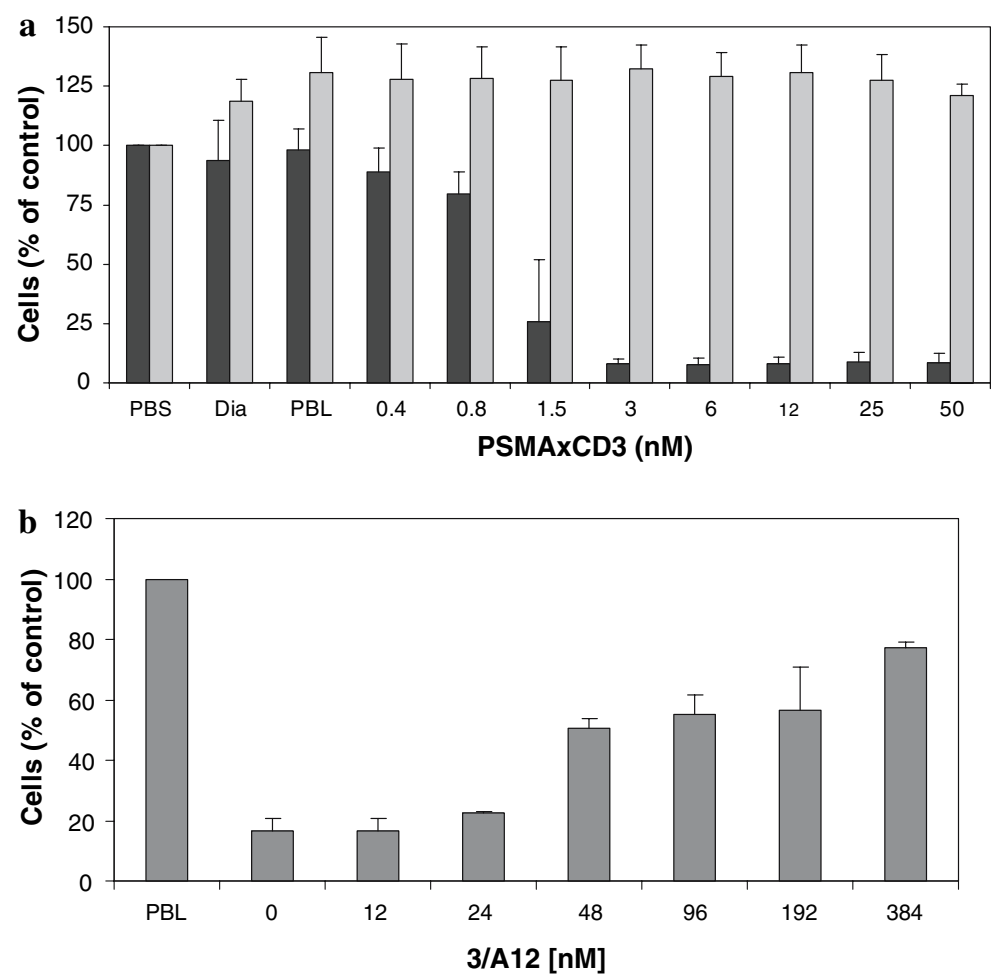

Fig. 6 a Effects of treatment of PSMA-positive C4-2 cells (black) and PSMA-negative DU 145 cells (gray) with PSMAxCD3 diabody and PBL effector cells (effector:target ratio 10:1). Cell viability was measured in WST assays after $48 \mathrm{~h}$ incubation as described. The results are expressed as the percentage of viable cells compared to the control (= cells incubated with PBS). Additionally, the data of treatment with diabody alone at $15 \mathrm{nM}$ without PBL (Dia) and the data of treatment with PBL alone without diabody (PBL) are given. The results were corrected for the background of the effector cells. Data represent mean values of determinations with three different blood donors each in triplicate. Standard deviations (SD) are indicated by the error bars. b Blocking of the cytotoxic activity of the PSMAxCD3 diabody by an excess of parental anti-PSMA mAb. C4-2 cells were incubated with $\mathrm{PBL}$ and diabody at $12 \mathrm{nM}$ together with parental mAb 3/A12 at different concentrations. Cell viability was measured in WST assays after $48 \mathrm{~h}$ incubation. Determination was with three different donors. SD are indicated by the error bars
Fig. 7 Effects of treatment of PSMA-positive C4-2 cells with PSMAxCD3 diabody (black) or anti-PSMA scFv (gray) or anti$\mathrm{CD} 3 \mathrm{scFv}$ (white) and PBL. (WST assay, E:T ratio 10:1, incubation time $48 \mathrm{~h}$ ). The results are expressed as the percentage of viable cells compared to the control $(=$ cells treated with PBS). Data represent mean values of three determinations with different donors. SD are indicated by the error bars

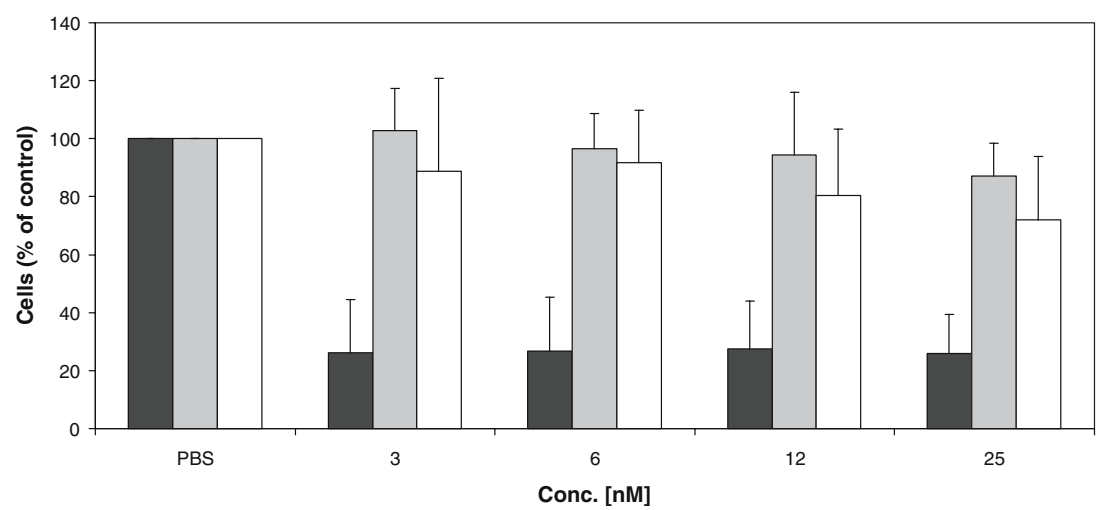

65 A. This size has been suggested as being optimal because it provides rapid tissue penetration, high target retention and rapid blood clearance [12]. Interestingly, our PSMAxCD3 diabody proved to be a tetramer as analyzed by BN-PAGE. This indicates the presence of two binding sites each for CD3 and PSMA. Kipriyanov et al. have shown that a tetravalent CD3 $\times$ CD19 tandem diabody was superior to the corresponding heterodimeric diabody [15]. 


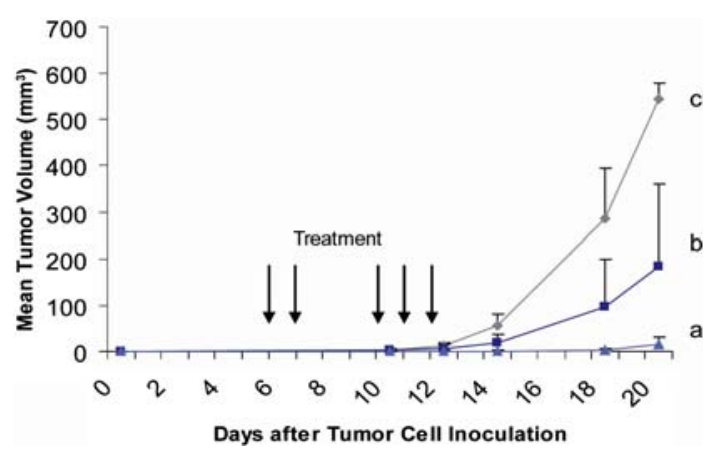

Fig. 8 Treatment of C4-2 xenografted SCID mice with PSMAxCD3 diabody. Mice were inoculated with $2 \times 10^{6} \mathrm{C} 4-2$ cells on day 0 and treated as follows: group a: $5 \times 10^{6}$ human PBL on day 6 after tumor inoculation and additionally $10 \mu \mathrm{g}$ PSMAxCD3 diabody on day 6,7 , 10, 11 and 12; group b: $5 \times 10^{6}$ human PBL on day 6; group c: PBS vehicle. The mean tumor volume is shown for each group. SD are indicated by the error bars

Currently it is not known whether our diabody forms a dimer of dimers or whether it is a bispecific tetrabody [12]. Flow cytometry measurements have shown that it binds to CD3-positive Jurkat cells and to PSMA-positive C4-2 cells with an affinity similar to that of the parental scFvs. In vitro testing showed the diabody's ability to induce an efficient lysis of PSMA-expressing target cells by human PBL. Furthermore, the diabody has proven to be clearly more effective than either of the parental scFv alone. However, in this in vitro test the antitumor activity of the diabody was not enhanced in the presence of anti-CD28 mAb, which induces a well-known co-stimulatory signal [4]. This may be partly explained by the use of preactivated PBL and is in accordance with other in vitro and in vivo studies $[9,16$, $18,25]$.

The ultimate goal of any antitumor immunotherapy is the in vivo eradication of tumor cells. In a first animal experiment we tested the potency of the PSMAxCD3 diabody to mediate T-cell dependent tumor lysis in a fairly stringent in vivo model of immunodeficient mice bearing a subcutaneously growing human prostate cancer xenograft. The therapy scheme was chosen according to literature suggestions [24] and aimed to treat small tumor masses. Therefore, we started the application of preactivated PBL and diabody as early as 6 days after tumor inoculation. With this treatment regime we could show that the PSMAxCD3 diabody is effective against prostate cancer cells in vivo in the absence of any T-cell co-stimulatory compounds. The efficacy under these conditions supports that human T-cells did reach the tumor site after injection into the tail vein and could act sufficiently long with a sufficient number of functional T-cells. The limited number and accessibility of human T-cells in our model may underestimate the potential of the PSMAxCD3 diabody in humans where cytotoxic $\mathrm{T}$-cells are present in larger numbers and found widespread in the organism. This availability of T-cells would make a repeated application of the diabody much more efficient, raising the opportunity to treat larger tumor masses. The current mouse model rather allows the investigation of a minimal residual disease situation. This is in agreement with other authors who showed good antitumor effects in human B-lymphoma xenografts after application of CD19 $\times$ CD3 diabody within a few days after tumor inoculation $[6,7]$. A direct comparison of early and late diabody application was shown by Schlereth et al. [24] in a human colon carcinoma xenograft model after application of an EP-CAMxCD3 diabody. These authors also found a much better tumor remission rate in the groups with early application due to a limited half-life of human lymphocytes in the SCID mouse, a smaller workload for the cytotoxic T-cells and an increased penetration in smaller tumors.

In comparison to other models, a shortcoming of our C42 xenograft model is the short experimental time. Since the C4-2 tumors are very fast growing and mostly ulcerating, the animals had to be euthanized 20-25 days after tumor inoculation. A slower growing cell line that allows longer observation times may be used in further studies. For further preclinical development, pharmacological properties as well as immunological side effects have to be tested in an immunocompetent individual. However, since the CD19 $\times$ CD3 diabody could be safely applied to chimpanzees [26], and also used in a first clinical trial [12], no severe side effects like a cytokine storm in the Phase I trial of the anti-CD28 monoclonal antibody [27] may be expected with the PSMAxCD3 diabody.

In conclusion, the present study describes a first approach to establish a new immunotherapy with retargeting of effector $\mathrm{T}$ cells for prostate cancer. We have demonstrated that the PSMAxCD3 diabody induces highly efficient T-cell mediated killing of prostate cancer cells. Therefore, this diabody deserves further development in preclinical and clinical settings as a promising therapeutic agent.

Acknowledgments We thank Dr. Kipriyanov for providing the plasmids pHOG-3-19, pHOG-19-3 and pHOG-CD3. This work was supported by an Emmy Noether fellowship and grant SFB620 from the German Research Council (DFG) to W.W.S.

\section{References}

1. Bohlen H, Hopff T, Manzke O, Engert A, Kube D, Wickramanayake PD, Diehl V, Tesch H (1993) Lysis of malignant B cells from patients with B-chronic lymphocytic leukemia by autologous $\mathrm{T}$ cells activated with CD3 $\times$ CD19 bispecific antibodies in combination with bivalent CD28 antibodies. Blood 82:1803-1812

2. Bolhuis RL, Hoogenboom HR, Gratama JW (1996) Targeting of peripheral blood T lymphocytes. Springer Semin Immunopathol $18: 211-226$ 
3. Canevari S, Stoter G, Arienti F, Bolis G, Colnaghi MI, Di Re EM, Eggermont AM, Goey SH, Gratama JW, Lamers CH, et al. (1995) Regression of advanced ovarian carcinoma by intraperitoneal treatment with autologous $\mathrm{T}$ lymphocytes retargeted by a bispecific monoclonal antibody. J Natl Cancer Inst 87:1463-1469

4. Chambers CA, Allison JP (1999) Costimulatory regulation of T-cell function. Curr Opin Cell Biol 11:203-210

5. Chang SS, Reuter VE, Heston WD, Bander NH, Grauer LS, Gaudin PB (1999) Five different anti-prostate-specific membrane antigen (PSMA) antibodies confirm PSMA expression in tumorassociated neovasculature. Cancer Res 59:3192-3198

6. Cochlovius B, Kipriyanov SM, Stassar MJ, Christ O, Schuhmacher J, Strauss G, Moldenhauer G, Little M (2000) Treatment of human B cell lymphoma xenografts with a CD3 $\times$ CD19 diabody and T cells. J Immunol 165:888-895

7. Dreier T, Baeuerle PA, Fichtner I, Grun M, Schlereth B, Lorenczewski G, Kufer P, Lutterbuse R, Riethmuller G, Gjorstrup P, Bargou RC (2003) T-cell costimulus-independent and very efficacious inhibition of tumor growth in mice bearing subcutaneous or leukemic human B-cell lymphoma xenografts by a CD19-/CD3-bispecific single-chain antibody construct. J Immunol 170:4397-4402

8. Elsasser-Beile U, Wolf P, Gierschner D, Buhler P, Schultze-Seemann W, Wetterauer U (2006) A new generation of monoclonal and recombinant antibodies against cell-adherent prostate specific membrane antigen for diagnostic and therapeutic targeting of prostate cancer. Prostate 66:1359-1370

9. Gao Y, Xiong D, Yang M, Liu H, Peng H, Shao X, Xu Y, Xu C, Fan D, Qin L, Yang C, Zhu Z (2004) Efficient inhibition of multidrug-resistant human tumors with a recombinant bispecific anti-Pglycoprotein $\mathrm{x}$ anti-CD3 diabody. Leukemia 18:513-520

10. Ghosh A, Heston WD (2004) Tumor target prostate-specific membrane antigen (PSMA) and its regulation in prostate cancer. J Cell Biochem 91:528-539

11. Grauer LS, Lawler KD, Marignac JL, Kumar A, Goel AS, Wolfert RL (1998) Identification, purification, and subcellular localization of prostate-specific membrane antigen $\mathrm{PSM}^{\prime}$ protein in the $\mathrm{LNCaP}$ prostatic carcinoma cell line. Cancer Res 58:4787-4789

12. Holliger P, Hudson PJ (2005) Engineered antibody fragments and the rise of single domains. Nat Biotechnol 23:1126-1136

13. Jemal A, Tiwari RC, Murray T, Ghafoor A, Samuels A, Ward E, Feuer EJ, Thun MJ (2004) Cancer statistics, 2004. CA Cancer J Clin 54:8-29

14. Kipriyanov SM, Moldenhauer G, Martin AC, Kupriyanova OA, Little M (1997) Two amino acid mutations in an anti-human CD3 single chain Fv antibody fragment that affect the yield on bacterial secretion but not the affinity. Protein Eng 10:445-453

15. Kipriyanov SM, Moldenhauer G, Schuhmacher J, Cochlovius B, Von der Lieth CW, Matys ER, Little M (1999) Bispecific tandem diabody for tumor therapy with improved antigen binding and pharmacokinetics. J Mol Biol 293:41-56

16. Kipriyanov SM, Moldenhauer G, Strauss G, Little M (1998) Bispecific CD3 $\times$ CD19 diabody for T-cell mediated lysis of malignant human B cells. Int J Cancer 77:763-772

17. Liu H, Moy P, Kim S, Xia Y, Rajasekaran A, Navarro V, Knudsen B, Bander NH (1997) Monoclonal antibodies to the extracellular domain of prostate-specific membrane antigen also react with tumor vascular endothelium. Cancer Res 57:3629-3634

18. Loffler A, Kufer P, Lutterbuse R, Zettl F, Daniel PT, Schwenkenbecher JM, Riethmuller G, Dorken B, Bargou RC (2000) A recombinant bispecific single-chain antibody, CD19 $\times$ CD3, induces rapid and high lymphoma-directed cytotoxicity by unstimulated T lymphocytes. Blood 95:2098-2103

19. MacDonald GC, Glover N (2005) Effective tumor targeting: strategies for the delivery of armed antibodies. Curr Opin Drug Discov Devel 8:177-183
20. Murphy GP, Greene TG, Tino WT, Boynton AL, Holmes EH (1998) Isolation and characterization of monoclonal antibodies specific for the extracellular domain of prostate- specific membrane antigen. J Urol 160:2396-2401

21. Perisic O, Webb PA, Holliger P, Winter G, Williams RL (1994) Crystal structure of a diabody, a bivalent antibody fragment. Structure 2:1217-1226

22. Schagger H, Cramer WA, von Jagow G (1994) Analysis of molecular masses and oligomeric states of protein complexes by blue native electrophoresis and isolation of membrane protein complexes by two-dimensional native electrophoresis. Anal Biochem 217:220-230

23. Schamel WW, Reth M (2000) Monomeric and oligomeric complexes of the B cell antigen receptor. Immunity 13:5-14

24. Schlereth B, Fichtner I, Lorenczewski G, Kleindienst P, Brischwein K, da Silva A, Kufer P, Lutterbuese R, Junghahn I, Kasimir-Bauer S, Wimberger P, Kimmig R, Baeuerle PA (2005) Eradication of tumors from a human colon cancer cell line and from ovarian cancer metastases in immunodeficient mice by a single-chain Ep-CAM-/CD3-bispecific antibody construct. Cancer Res 65:2882-2889

25. Schlereth B, Kleindienst P, Fichtner I, Lorenczewski G, Brischwein K, Lippold S, da Silva A, Locher M, Kischel R, Lutterbuse R, Kufer P, Baeuerle PA (2006) Potent inhibition of local and disseminated tumor growth in immunocompetent mouse models by a bispecific antibody construct specific for Murine CD3. Cancer Immunol Immunother 55:785-796

26. Schlereth B, Quadt C, Dreier T, Kufer P, Lorenczewski G, Prang N, Brandl C, Lippold S, Cobb K, Brasky K, Leo E, Bargou R, Murthy K, Baeuerle PA (2006) T-cell activation and B-cell depletion in chimpanzees treated with a bispecific anti-CD19/anti-CD3 single-chain antibody construct. Cancer Immunol Immunother 55:503-514

27. Suntharalingam G, Perry MR, Ward S, Brett SJ, Castello-Cortes A, Brunner MD, Panoskaltsis N (2006) Cytokine storm in a phase 1 trial of the anti-CD28 monoclonal antibody TGN1412. N Engl J Med 355:1018-1028

28. Swamy M, Kulathu Y, Ernst S, Reth M, Schamel WW (2006) Two-dimensional Blue Native-/SDS-PAGE analysis of SLP family adaptor protein complexes. Immunol Lett 104:131-137

29. Swamy M, Siegers GM, Minguet S, Wollscheid B, Schamel WW (2006) Blue native polyacrylamide gel electrophoresis (BNPAGE) for the identification and analysis of multiprotein complexes. Sci STKE 345:14

30. Wang S, Diamond DL, Hass GM, Sokoloff R, Vessella RL (2001) Identification of prostate-specific membrane antigen (PSMA) as the target of monoclonal antibody $107-1 \mathrm{~A} 4$ by proteinchip; array, surface-enhanced laser desorption/ionization (SELDI) technology. Int J Cancer 92:871-876

31. Weiner GJ, Degast GC (1995) Bispecific monoclonal antibody therapy of B-cell malignancy. Leuk Lymphoma 16:199-207

32. Wolf H, Freimann U, Jung G (1994) Target cell induced T-cell activation with bispecific antibodies: a new concept for tumor immunotherapy. Recent Results Cancer Res 135:185-195

33. Wolf P, Gierschner D, Buhler P, Wetterauer U, Elsasser-Beile U (2006) A recombinant PSMA-specific single-chain immunotoxin has potent and selective toxicity against prostate cancer cells. Cancer Immunol Immunother 55:1367-1373

34. Wu AM, Chen W, Raubitschek A, Williams LE, Neumaier M, Fischer R, Hu SZ, Odom-Maryon T, Wong JY, Shively JE (1996) Tumor localization of anti-CEA single-chain Fvs: improved targeting by non-covalent dimers. Immunotechnology 2:21-36 